\title{
BMJ Open Association between asthma and dry eye disease: a meta-analysis based on observational studies
}

\author{
Qun Huang (D) , ${ }^{1,2}$ Yanlin Zheng, ${ }^{1,2}$ Chuantao Zhang, ${ }^{3}$ Wanjie Wang, ${ }^{1}$ Tingting Liao, ${ }^{4}$ \\ Xili Xiao, ${ }^{1}$ Jing Wang, ${ }^{1}$ Juan Wang ${ }^{1}$
}

To cite: Huang Q, Zheng $Y$, Zhang C, et al. Association between asthma and dry eye disease: a meta-analysis based on observational studies. BMJ Open 2021;11:e045275. doi:10.1136/ bmjopen-2020-045275

- Prepublication history for this paper is available online. To view these files, please visit the journal online (http://dx.doi org/10.1136/bmjopen-2020045275).

Received 11 0ctober 2020 Accepted 20 0ctober 2021

Check for updates

(C) Author(s) (or their employer(s)) 2021. Re-use permitted under CC BY-NC. No commercial re-use. See rights and permissions. Published by BMJ.

${ }^{1}$ Ophthalmology, Hospital of Chengdu University of Traditional Chinese Medicine, Chengdu, Sichuan, China

${ }^{2}$ Clinical Medical College, Chengdu University of Traditional Chinese Medicine, Chengdu, Sichuan, China

${ }^{3}$ Department of Respiratory Medicine, Hospital of Chengdu University of Traditional Chinese Medicine, Chengdu, Sichuan,

China

${ }^{4}$ Department of Endocrinology, Hospital of Chengdu University of Traditional Chinese Medicine, Chengdu, China

Correspondence to

Professor Yanlin Zheng;

zhengyanlin@cdutcm.edu.cn

\section{ABSTRACT}

Objective This study aimed to systematically review the relationship between dry eye disease (DED) and asthma based on published population-based studies.

Data sources PubMed, EMBASE and ISI Web of Science from their inception were searched up to October 2019. Study selection Observational studies addressing the association between asthma and DED will be eligible. Data extraction and synthesis Two reviewers independently conducted the data extraction and quality assessment. We used a random-effects model for all analyses. Subgroup analysis according to ethnicity was performed to test the influence of ethnicity on the association.

Main outcomes and measures Six independent studies (a total of 45215 patients with asthma and 232864 control subjects) were included in this review and had an average of seven stars by the Newcastle-Ottawa Scale. Our current findings suggest that the prevalence of DED was higher in the asthma group than in the control group $(Z=7.42, p<0.00001 ; 0 R 1.29,95 \% \mathrm{Cl} 1.20$ to 1.38$)$. In the subgroup analysis by ethnicity, Australian, Caucasian and Asian patients with asthma showed an increased risk of DED.

\section{INTRODUCTION}

Dry eye disease (DED) has been the focus of attention in recent years, as it is one of the main reasons for seeking eye care in eye clinics. ${ }^{1}$ According to surveys, the prevalence of DED is estimated to be between $5 \%$ and $50 \%,{ }^{2-8}$ the frequency of which increases with age. ${ }^{9}$ The prevalence is driven mainly by the classification of DED, with the prevalence of signs being much higher (up to $75 \%$ ) compared with symptoms. ${ }^{8}$ The economic burden and impact of DED is considerable in terms of vision, quality of life, work productivity and the psychological and physical impact of pain. Therefore, indirect costs account for the largest proportion of total costs because of the significant decline in work efficiency. 81011

DED is considered to be a multifactorial disease of the ocular surface characterised by a loss of homoeostasis of the tear film

\section{Strengths and limitations of this study}

To the best of our knowledge, this is the first systematic review and meta-analysis to assess the association between asthma and dry eye disease (DED).

- Six included studies achieved an average of seven stars, and two studies gained nine stars according to the Newcastle-Ottawa Scale.

- Due to geographical and cultural differences, the lack of universal diagnostic criteria can affect the association between asthma and the incidence of DED.

- This significant association may not reflect a causal effect due to the cross-sectional design of the included studies.

accompanied by ocular symptoms, in which tear film instability and hyperosmolarity, ocular surface inflammation and damage, and neurosensory abnormalities play etiological roles. ${ }^{12}$ Clear factors currently known to be associated with the onset of DED include age, sex and hormones, but in recent years, it has also been found that DED is associated with asthma, allergic rhinitis and atopic dermatitis. $^{13}$

Asthma is one of the most common chronic immunological diseases in humans, affecting $1 \%-18 \%$ of the population in different countries. ${ }^{14}$ Specifically, the prevalence of asthma varies depending on whether the disease is diagnosed by a medical doctor $(4.3 \%)$, clinical/treated asthma $(4.5 \%)$, or symptoms such as wheezing $(8.6 \%)$ and varies by up to 21 times in different countries. ${ }^{15}$ Its mortality rate is estimated to 0.19 deaths per 100000 people. ${ }^{1617}$ The aetiology of asthma is multifactorial, including atopic sensitisation, ${ }^{18}$ viral respiratory infections, ${ }^{19}$ environmental exposures, ${ }^{20}$ obesity $^{21}$ and smoking. ${ }^{22}$ Asthma is considered to be the result of complex genetic-environmental interactions, with heterogeneity in the clinical manifestations 
and the type and intensity of airway inflammation and remodelling. ${ }^{23}$

Increasing evidence suggests that DED is associated with a high risk of ocular allergy. ${ }^{24} 25$ Ocular allergy, particularly the severe forms of keratoconjunctivitis, has an impact on different key mechanisms of DED, including tear film instability, ocular surface inflammation and damage, and neurosensory abnormalities. ${ }^{26}$ Moreover, patients with asthma also often have allergic comorbidities such as allergic rhinitis, allergic conjunctivitis, atopic dermatitis, food allergy and drug allergy. ${ }^{27}{ }^{28}$ Recently, several studies have highlighted the possible relationship between DED and asthma. ${ }^{29}{ }^{30}$ However, a possible relationship between asthma and DED remains under investigation, and wellestablished information is very limited. To the best of our knowledge, no meta-analysis has been performed to assess the relationship between asthma and DED. Thus, we performed the current meta-analysis to determine whether there is a link between asthma and DED using a meta-analytic approach to quantify such associations.

\section{METHODS}

This systematic review and meta-analysis conformed to the Preferred Reporting Items for Systematic Reviews and Meta-Analyses guidelines. ${ }^{31}$

\section{Literature search strategy}

Referring to the search strategy suggested by Cochrane, two researchers independently and systematically searched three electronic databases, including PubMed, EMBASE and ISI Web of Science, from the database inception date to 1 October 2019, without language restrictions. A combination of Medical Subject Terms (MeSHs) and free terms was used to retrieve possibly eligible publications in each electronic database, and the English search strategy was as follows: (asthma or "Asthma" $[\mathrm{MeSH}]$ ) and (dry eye or dry eye disease or "dry eye syndrome" [MeSH]). For Chinese academic databanks, we used 'Gan Yan' and 'Xiao chuan' to identify relevant Chinese articles. We also manually screened the reference lists of the original and review articles for additional eligible studies.

\section{Inclusion criteria}

The inclusion criteria were as follows: (1) the diagnosis of asthma and DED in the study group was based on wellestablished criteria or according to a clinical diagnosis made by clinical physicians; (2) control subjects should be free of any history of asthma or DED, no specific restriction on sex and age was imposed; (3) types of study were observational studies, including cross-sectional, cohort, case-control or epidemiological studies and (4) the main outcome was the association between DED and asthma, as indicated by OR and the associated 95\% CIs, which should be either provided directly in the original article or could be calculated based on the original data. If studies with overlapping participants were encountered, reports with the largest sample and the most recent reports were included in the present meta-analysis. If no data were available in the original article, the corresponding author of the relevant study was contacted via email. If the corresponding author did not respond after we sent three emails, this article was not used for quantitative synthesis. Abstracts, editorial letters, reviews, case reports, book chapters and organisational guidelines were excluded from the analysis.

\section{Data extraction}

According to the predetermined inclusion criteria, two reviewers (XX and JW) independently conducted the literature search, data extraction and quality assessment and were blinded to the findings of the other reviewer. After rigorous screening, the following data regarding the characteristics of the studies were extracted using a standardised collection form: first author, year of publication, country where the study was conducted, sample size, demographic characteristics of participants in different groups, strategies for confirmation of DED and asthma, and adjustment of confounding factors for effect assessment. Disagreements that occurred during the study selection were resolved through a discussion with a third reviewer (YZ) until a consensus was reached.

\section{Quality assessment}

The Newcastle-Ottawa Scale (NOS) was used to assess the risk of bias in case-control and cohort studies. ${ }^{32}$ The methodological quality of the cross-sectional studies was evaluated according to the standards of the Agency for Healthcare Research and Quality. ${ }^{33}$ Two reviewers (WW and JW) independently conducted quality assessments of the included studies and compared the results. The third reviewer (YZ) was consulted in case of discrepancies regarding quality assessment.

\section{Data synthesis and analysis}

RevMan V.5.3 (Copenhagen: the Nordic Cochrane Center, the Cochrane Collaboration, 2014) was used for the meta-analysis and subgroup analysis. The association between asthma and DED was estimated using adjusted OR and unadjusted OR, and the upper and lower limits of the $95 \%$ CI were extracted from each study. The confounding factors included age and sex. Before combining the data from the included studies, statistical heterogeneity among studies for each outcome was estimated using a standard $\chi^{2}$ test and the Higgins $\mathrm{I}^{2}$ test $\left(\mathrm{p}>0.1, \mathrm{I}^{2}<50 \%\right.$ indicated acceptable heterogeneity $\left.^{34}\right)$. In the meta-analyses of multiple studies for a specific outcome, a random-effects model was calculated for pooling data across studies if statistical heterogeneity existed; however, if a low heterogeneity was detected in the meta-analysis, a random-effects model was also calculated, as the validity of tests of heterogeneity could be limited with a small number of component studies. In the case of high heterogeneity, subgroup analysis was carried out by ethnicity, as it was the only confounding factor consistently presented in our selected studies. 


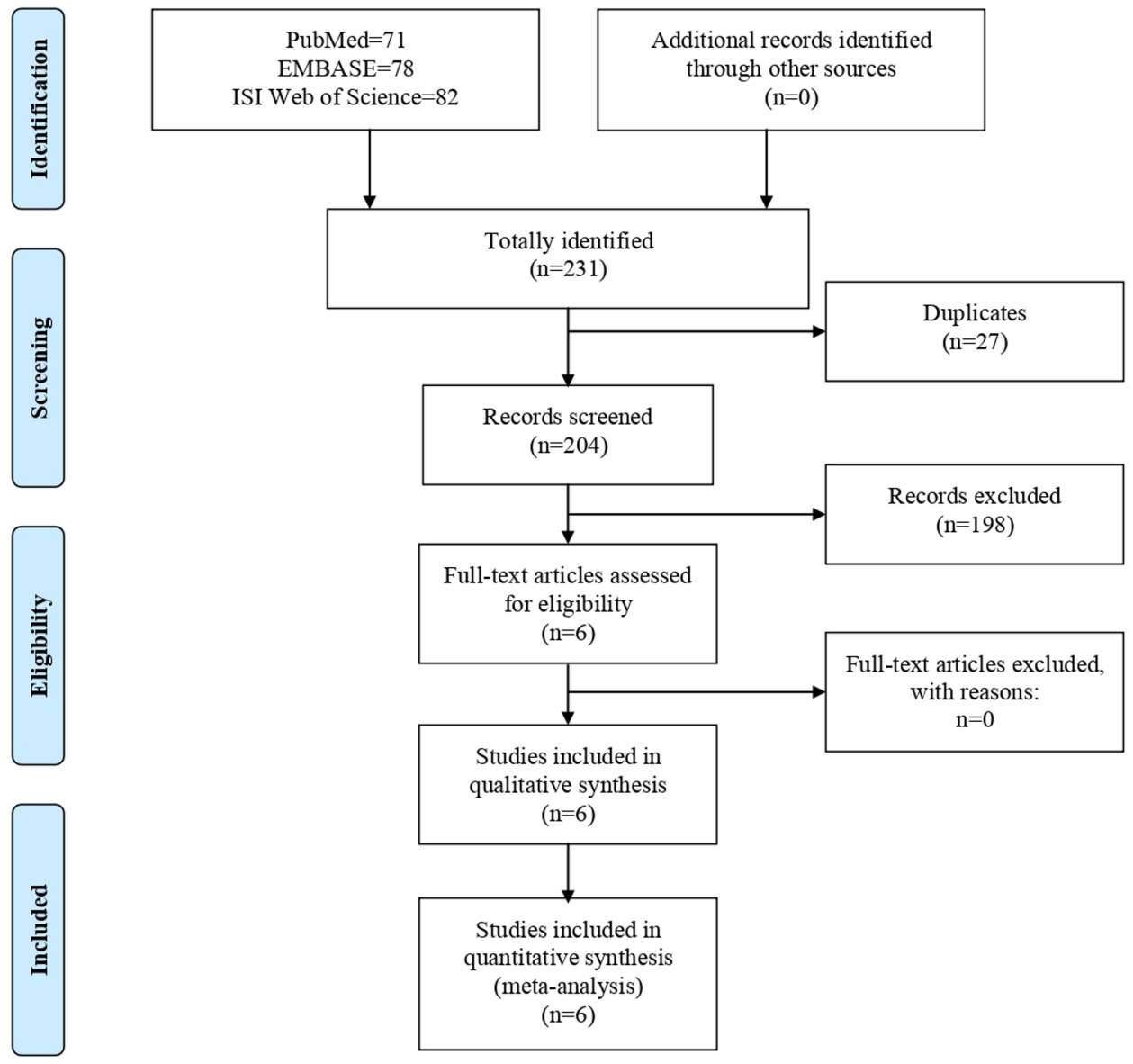

Figure 1 Flow chart of literature search.

Sensitivity analysis was conducted by omitting one study at a time and evaluating the resulting effect to determine the potential source of heterogeneity. Begg's rank correlation test and Egger's linear regression test using Stata V.12.0 (StataCorp) were used to evaluate publication bias. Statistical significance was set at $\mathrm{p}<0.05$ (one sided), except for tests of heterogeneity.

\section{Patient and public involvement}

There was no involvement of patients or public during the outline of this project.

\section{RESULTS}

\section{Literature search}

A total of 231 potential literature citations were searched initially, including 71 records from PubMed, 78 from EMBASE, and 82 from ISI Web of Science (figure 1). Additionally, 27 duplicate articles were excluded. Based on the predetermined selection criteria, 198 studies were excluded at the title and abstract stages, and 6 potentially relevant studies were selected and retrieved for fulltext reading and evaluation of data integrity. Finally, six studies $^{13} 2930$ 35-37 met all the inclusion criteria for this systematic review and were included.

\section{Study characteristics}

Overall, the sample sizes of the included studies ranged from 1174 to 105794 , of which a total of 45215 patients with asthma and 232864 control subjects were included. The included studies were published between 2003 and 2018 and involved different ethnicities, including Arabian, Australian, Asian and Caucasian populations. The assessment of asthma and DED was inconsistent between studies, and detailed data on the main characteristics of these studies are shown in table 1 .

\section{Risk of bias assessment}

The methodological quality of the included studies was considered low to high, according to the NOS. Six included studies achieved an average of seven stars, and two studies ${ }^{2935}$ gained nine stars (table 2).

\section{Meta-analyses}

A random-effects model was selected to analyse the effect size with modest heterogeneity among the studies $\left(\mathrm{I}^{2}=23 \%, \mathrm{p}=0.26\right)$. The asthma group had a significantly higher prevalence of DED than the control group (OR $1.29,95 \%$ CI 1.20 to $1.38 ; \mathrm{p}<0.00001)$. In brief, there was a significant association between asthma and DED (figure 2). Owing to the lack of data, it was not possible 


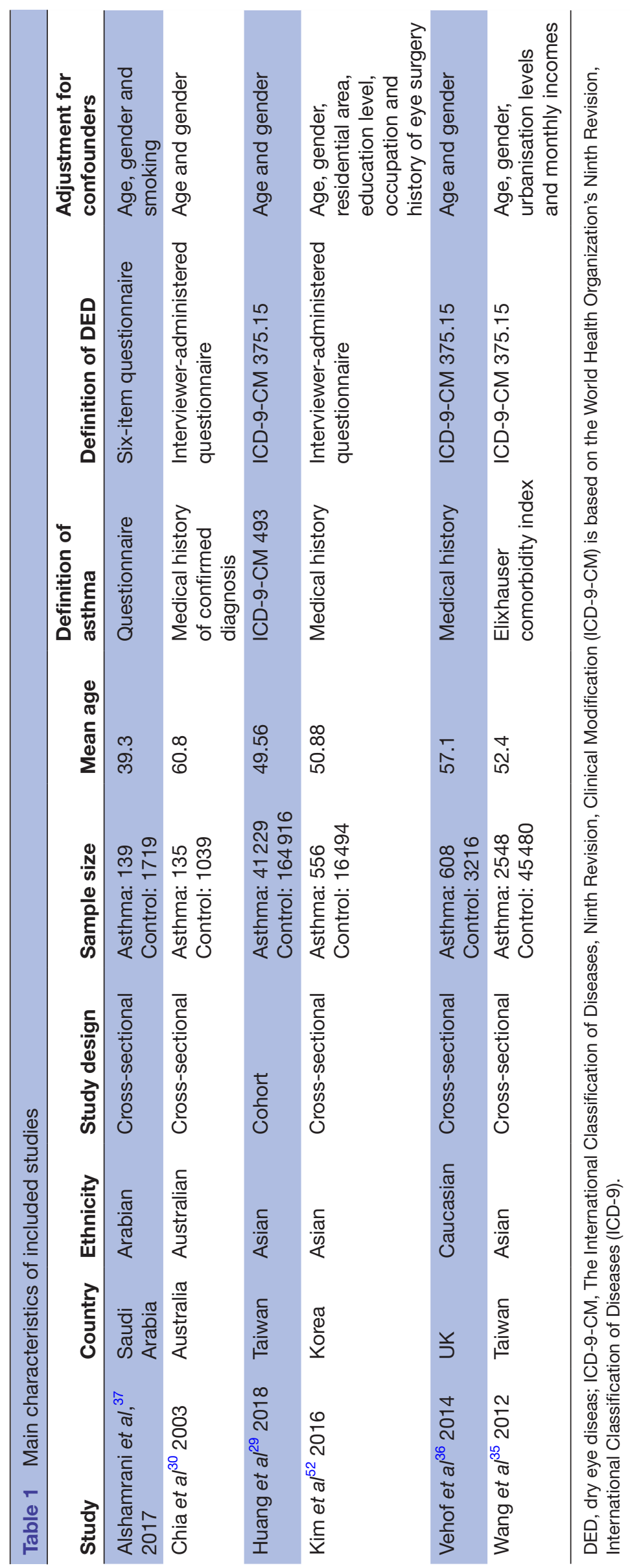


Table 2 Quality assessment of included studies according to the Newcastle-Ottawa Scale

\begin{tabular}{|c|c|c|c|c|c|c|}
\hline Item/study & $\begin{array}{l}\text { Alshamrani et } a l^{37} \\
2017\end{array}$ & $\begin{array}{l}\text { Chia et } \text { al }^{30} \\
2003\end{array}$ & $\begin{array}{l}\text { Huang et al }{ }^{29} \\
2018\end{array}$ & $\begin{array}{l}\text { Kim et al } \\
2016\end{array}$ & $\begin{array}{l}\text { Vehof et } a l^{36} \\
2014\end{array}$ & $\begin{array}{l}\text { Wang et } a l^{35} \\
2012\end{array}$ \\
\hline $\begin{array}{l}\text { Adequate definition of } \\
\text { cases }\end{array}$ & * & * & * & * & * & * \\
\hline $\begin{array}{l}\text { Representativeness of } \\
\text { cases }\end{array}$ & * & - & * & * & - & * \\
\hline $\begin{array}{l}\text { Selection of control } \\
\text { subjects }\end{array}$ & - & - & * & * & - & * \\
\hline $\begin{array}{l}\text { Definition of control } \\
\text { subjects }\end{array}$ & * & * & * & * & * & * \\
\hline $\begin{array}{l}\text { Control for important factor } \\
\text { or additional factor }\end{array}$ & - & - & ** & - & * & ** \\
\hline Exposure assessment & * & * & * & * & * & * \\
\hline Non-response rate & * & * & * & * & * & * \\
\hline
\end{tabular}

A study could be awarded a maximum of one star for each item except for the item 'Control for important factor or additional factor'.

The definition/explanation of each column of the Newcastle-Ottawa Scale is available from (http://www.ohri.ca/programs/clinical_ epidemiology/oxford.asp).

The NOS is used to assess the methodological quality of included studies using a "star" system. A study could be awarded a maximum of one star for each item except for the item "Control for important factor or additional factor". The "*" and "**" in table 2 actually stand for the number of stars each study can get.

to detect an association between asthma and diverse subtypes of DED.

\section{Subgroup analysis}

Subgroup analysis was performed according to ethnicity (figure 3). In the stratified analysis by ethnicity, a statistically significant correlation was detected in Australians (OR 1.60, 95\% CI 1.00 to 2.56; $\mathrm{p}=0.05$ ), Caucasians (OR $1.54,95 \%$ CI 1.17 to 2.03; $\mathrm{p}=0.002$ ) and Asians (OR 1.29, $95 \%$ CI 1.23 to $1.35 ; \mathrm{p}<0.00001)$, but this association was not significant among the Arabian population (OR 0.96, $95 \%$ CI 0.63 to $1.46 ; \mathrm{p}=0.85)$.

\section{Sensitivity analysis and publication bias}

The funnel plot for the association between asthma and DED was symmetrical in vision (figure 4 ). The Begg's test $(\mathrm{z}=0.38, \mathrm{p}=0.727)$ and Egger's test $(\mathrm{t}=-0.40, \mathrm{p}=0.708)$ also suggested no statistically significant publication bias.
A sensitivity analysis confirmed the robustness of our conclusions (detailed data not shown).

\section{DISCUSSION}

To the best of our knowledge, this is the first systematic review and meta-analysis to assess the association between asthma and DED, which examined a large dataset of six studies with a total of 278079 participants. Our current findings suggest that asthma patients have a higher risk of developing DED than non-asthmatic patients, and this significant correlation could be observed in different ethnicities, except for Arabians. In the subgroup analysis of study location, Australian, Caucasian and Asian patients with asthma showed an increased risk of DED. It cannot be ignored that dry eye questionnaires are not only useful tools for characterising the type and severity

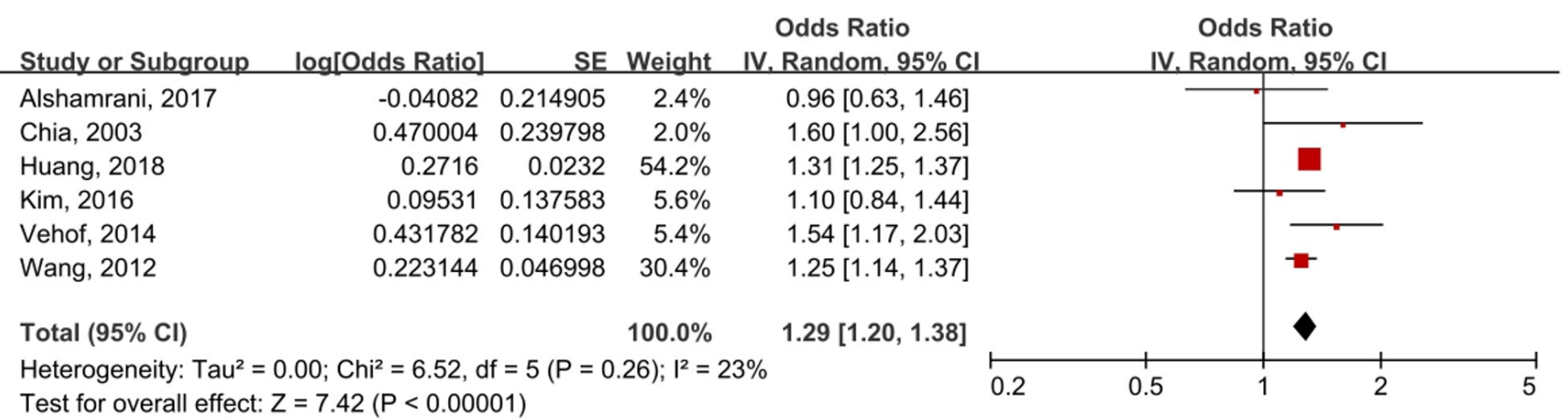

Figure 2 Meta-analysis of asthma and DED using a random-effects model. DED, dry eye disease; IV, inverse variance. 


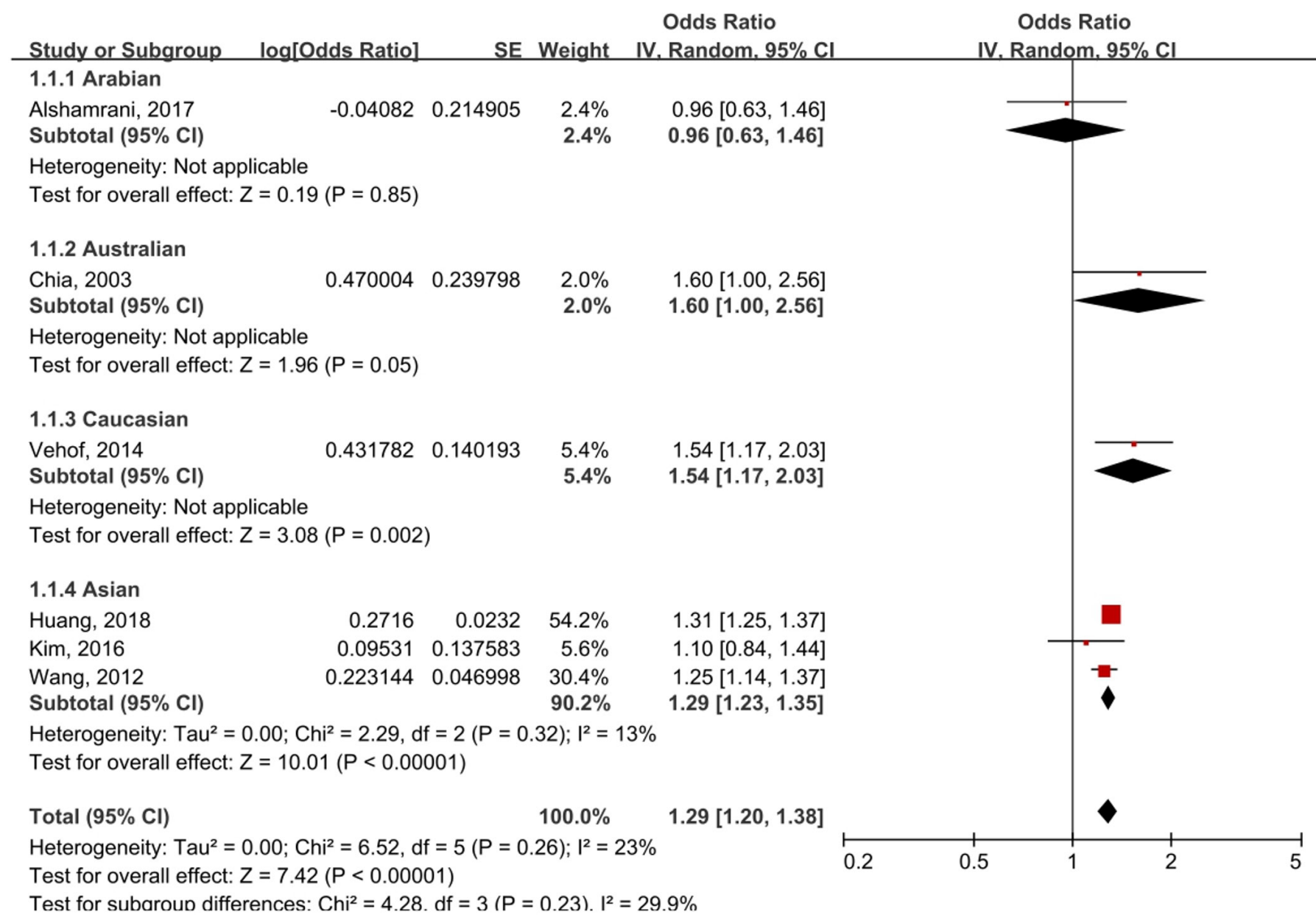

Figure 3 Subgroup analysis by ethnicity of asthma and DED. DED, dry eye disease; IV, inverse variance.

of dry eye, but also for evaluating the effectiveness of therapeutic interventions. Therefore, in at least $50 \%$ of the observational studies included in this meta-analysis, the diagnosis of DED was based on survey instruments (questionnaires) rather than on a clinical basis.

Some population-based studies have emphasised the possible relationship between DED and asthma. Chia et $a l^{30}$ found that after adjusting for age and sex factors,

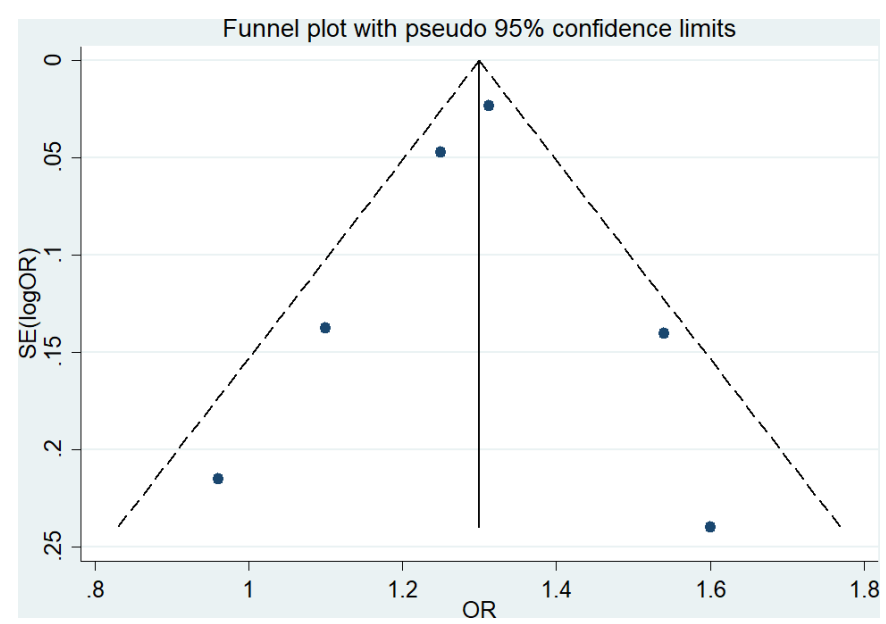

Figure 4 Funnel plot of a meta-analysis of asthma and DED. DED, dry eye disease. asthma is a systemic factor closely related to DED. Dogru et $a l^{38}$ found that the mean measurement of tear film breakup time was significantly lower in asthma patients than in controls, and the presence of tear film instability was higher in children with asthma, which may lead to DED in the future. In addition, in terms of treatment, some studies found that patients receiving asthmarelated treatments (including leukotriene receptor antagonists, antihistamines and inhaled corticosteroids) have a higher risk of DED, among which antihistamines were the most frequently reported. Antihistamines are widely used to relieve allergic symptoms. However, it should not be ignored that antihistamines have a muscarinic effect on the surrounding muscarinic receptors, thereby reducing the production of tears by reducing mucin output from the goblet cells. ${ }^{39}$ Therefore, the use of antihistamines to treat allergic diseases, including asthma, induces or exacerbates the signs and symptoms of DED. ${ }^{40-42}$ Several studies have reported that antihistamines may be associated with DED, ${ }^{43} 44$ and Bielory ${ }^{39}$ found that anti-inflammatory agents used in the treatment of asthma and allergy may exacerbate dry eye complaints that commonly complicate symptoms with various forms of tear film dysfunction or conjunctival hyperreactivity. 
With the emergence of many risk factors for DED, environmental conditions are associated with the occurrence and persistence of the disease. ${ }^{45}$ One study showed that exposure to adverse environmental conditions, especially bioaerosols and air pollution, has a serious negative impact on DED symptoms. ${ }^{46}$ This finding is largely consistent with other literature because elevated levels of air pollutants and microorganisms have been related to adverse health outcomes, including asthma and immune disorders. ${ }^{47} 48$ Since our eyes are directly exposed to the air, the composition and characteristics of the air will undoubtedly change the anterior corneal tear film and affect the corneal nerve function. ${ }^{49}$ Air pollution is the indicator most often associated with DED ${ }^{50}{ }^{51}$ In addition, exposures to other pollutants have been found to be in association to symptoms and signs of DED. For example, changes in ground-level ozone concentrations are closely related to changes in DED parameters, including tear secretion and Ocular Surface Disease Index scores. ${ }^{52}$ Both air pollutants and microbial contamination may contribute to the worsening of DED symptoms, possibly because both are associated with inflammation and oxidative stress. In animal studies, topical use of PM2.5 on mouse corneas has resulted in ocular surface damage similar to that of human dry eyes. ${ }^{53}{ }^{54}$ Humidity is also an interesting risk factor, because both low and high humidity have been shown to be related to DED. ${ }^{556}$ This may be because high humidity is conducive to the growth and survival of microorganisms in the air, while low humidity leads to aqueous loss. ${ }^{56}$

Asthma is a consequence of complex gene-environment interactions and is an inflammatory response triggered by exposure to allergens, infection, or irritants. ${ }^{23} 57$ Innate and adaptive cells, including eosinophils, mast cells, lymphocytes, neutrophils and monocytes, are activated to express or derive cytokines and chemokines and enhance inflammation and airway hyper-responsiveness, leading to airway remodelling. ${ }^{58}$ In contrast, the most widely accepted hypothesis for the pathogenesis of DED is the immunological mechanism ${ }^{59}$ and inflammation. ${ }^{6061}$ There is potential for the ocular homoeostasis to be altered by innate and adaptive cells such as neutrophils, lymphocytes, eosinophils, NK cells and macrophages, resulting in inflammatory processes that compromise both the tear film and ocular surface integrity. ${ }^{62}$ Although the exact mechanism of DED and asthma is not completely clear, the pathogenesis of both diseases is closely related to inflammation, which may have some shared biological pathways.

In addition, most patients with allergic diseases, such as asthma, have allergic conjunctivitis. It is estimated that as many as $20 \%$ of adults and $44 \%$ of children with asthma have symptoms of allergic conjunctivitis. ${ }^{63}$ Allergic conjunctivitis itself can induce or aggravate dry eye by reducing the density of goblet cells and conjunctival mucin and destabilise the tear film. ${ }^{64}{ }^{65}$ In addition, DED and allergic conjunctivitis have certain similarities in signs and symptoms. ${ }^{66} 67$ Therefore, we cannot rule out the possibility that some allergic conjunctivitis in this population may be misdiagnosed as dry eye, and the results should be interpreted cautiously.

Asthma and DED are common clinical diseases, and there is still no evidence to support a causal relationship between asthma and DED, which may have a common pathophysiological mechanism even if they occur independently. Clinicians need to diagnose the possibility of both asthma and DED. Patients with asthma should strengthen the prevention and treatment of DED and try to avoid the risk factors of DED and iatrogenic DED, including the use of contact lenses and long-term use of visual display terminals, including refractive or cataract surgery. ${ }^{6869}$

\section{Limitations}

Our analysis included an in-depth and extensive literature search that included six studies, presented data of sufficient quality, and calculated outcome measures that were independent of the risk of research bias. However, our research has some limitations in the interpretation of the results. As a general defect in the meta-analysis of observational studies, we cannot rule out the possibility that certain residual factors may link asthma and DED, such as environmental factors and the use of asthma medications. Second, due to geographic and cultural differences, the lack of universal diagnostic criteria can affect the association between asthma and the incidence of DED. Finally, the results of this study do not indicate a causal relationship between asthma and DED. We recognise that this is a limitation; thus, the results should be interpreted cautiously.

\section{CONCLUSIONS}

The results of our meta-analysis show that asthma patients have a higher risk of developing DED than those without asthma, and this relationship is significant in Australians, Caucasians and Asians. However, this association may not reflect the cause and effect if unidentified confounders account for the results. These data suggest that patients with asthma may be at risk of developing a comorbid diagnosis of DED and should try to avoid risk factors and strengthen the prevention of DED.

Contributors QH had full access to all of the data in the study and takes responsibility for the integrity of the data and the accuracy of the data analysis. $\mathrm{QH}$ and $\mathrm{YZ}$ planned and designed the study. XX and JW conducted rigorous literature searches and data extraction. WW and JW conducted the data preparation, quality assessments and data analyses. $\mathrm{QH}$ and $\mathrm{CZ}$ wrote and revised the manuscript. All the authors read and approved the final manuscript.

Funding This work was supported by Sichuan Science and technology programprogramme(grant number 2020JDRC0114), 'Xinglin scholar' Research Premotion Project of Chengdu University of Traditional Chinese Medicine(grant number XSGG2019016, XGZX2003, JSZX005), '100 Talent Plan' Project of Hospital of Chengdu University of Traditional Chinese Medicine (grant number Hospital office (2020) 42), National training programme for innovative backbone talents of traditional Chinese Medicine (grant number No. 91 (2019) of the State Office of Traditional Chinese Medicine), Science and technology development fund of Hospital of Chengdu University of traditional Chinese Medicine (grant number 19LW19, 18MZ12. The funder has provided only financial support for the study. 
Competing interests None declared.

Patient and public involvement Patients and/or the public were not involved in the design, or conduct, or reporting, or dissemination plans of this research.

\section{Patient consent for publication Not applicable.}

Provenance and peer review Not commissioned; externally peer reviewed.

Data availability statement Data are available on reasonable request. All data relevant to the study are included in the article or uploaded as online supplemental information. Details of the characteristics of the included studies and data extracted are available from the corresponding author at zhengyanlin@cdutcm.edu.cn.

Open access This is an open access article distributed in accordance with the Creative Commons Attribution Non Commercial (CC BY-NC 4.0) license, which permits others to distribute, remix, adapt, build upon this work non-commercially, and license their derivative works on different terms, provided the original work is properly cited, appropriate credit is given, any changes made indicated, and the use is non-commercial. See: http://creativecommons.org/licenses/by-nc/4.0/.

ORCID iD

Qun Huang http://orcid.org/0000-0002-0544-1273

\section{REFERENCES}

1 Bradley JL, Özer Stillman I, Pivneva I, et al. Dry eye disease ranking among common reasons for seeking eye care in a large US claims database. Clin Ophthalmol 2019;13:225-32.

2 Dana R, Bradley JL, Guerin A, et al. Estimated prevalence and incidence of dry eye disease based on coding analysis of a large, All-age United States health care system. Am J Ophthalmol 2019;202:47-54.

3 Yasir ZH, Chauhan D, Khandekar R, et al. Prevalence and determinants of dry eye disease among 40 years and older population of Riyadh (except capital), Saudi Arabia. Middle East Afr J Ophthalmol 2019;26:27-32.

4 Tan LL, Morgan P, Cai ZQ, et al. Prevalence of and risk factors for symptomatic dry eye disease in Singapore. Clin Exp Optom 2015;98:45-53.

5 Song $\mathrm{P}$, Xia W, Wang M, et al. Variations of dry eye disease prevalence by age, sex and geographic characteristics in China: a systematic review and meta-analysis. J Glob Health 2018;8:020503.

6 Caffery B, Srinivasan S, Reaume CJ, et al. Prevalence of dry eye disease in Ontario, Canada: a population-based survey. Ocul Surf 2019;17:526-31.

7 Titiyal JS, Falera RC, Kaur M, et al. Prevalence and risk factors of dry eye disease in North India: ocular surface disease index-based cross-sectional hospital study. Indian J Ophthalmol 2018;66:207-11.

8 Stapleton F, Alves M, Bunya VY, et al. TFOS DEWS II epidemiology report. Ocul Surf 2017;15:334-65.

9 Rapoport Y, Singer JM, Ling JD, et al. A comprehensive review of sex disparities in symptoms, pathophysiology, and epidemiology of dry eye syndrome. Semin Ophthalmol 2016;31:325-36.

10 Uchino M. What we know about the epidemiology of dry eye disease in Japan. Invest Ophthalmol Vis Sci 2018;59:DES1-23491.

11 McDonald M, Patel DA, Keith MS, et al. Economic and Humanistic Burden of Dry Eye Disease in Europe, North America, and Asia: A Systematic Literature Review. Ocul Surf 2016;14:144-67.

12 Craig JP, Nichols KK, Akpek EK, et al. TFOS DEWS II definition and classification report. Ocul Surf 2017;15:276-83.

$13 \mathrm{Kim} \mathrm{M}$, Oh J-H, Park CY, et al. Dry eye disease and allergic conditions: a Korean nationwide population-based study. Am J Rhinol Allergy 2016;30:397-401.

14 GINA Executive and Science committee. Global strategy for asthma management and prevention, 2020. Available: https://ginasthma.org/ wp-content/uploads/2020/06/GINA-2020-report_20_06_04-1-wms. pdf [Accessed 5 Feb 2021].

15 To T, Stanojevic S, Moores G, et al. Global asthma prevalence in adults: findings from the cross-sectional World health survey. BMC Public Health 2012;12:204.

16 Ebmeier S, Thayabaran D, Braithwaite I, et al. Trends in international asthma mortality: analysis of data from the who mortality database from 46 countries (1993-2012). Lancet 2017;390:935-45.

17 Huang K, Yang T, Xu J, et al. Prevalence, risk factors, and management of asthma in China: a national cross-sectional study. Lancet 2019;394:407-18.

18 Holt PG, Sly PD. Viral infections and atopy in asthma pathogenesis: new rationales for asthma prevention and treatment. Nat Med 2012;18:726-35
19 Busse WW, Lemanske RF, Gern JE. Role of viral respiratory infections in asthma and asthma exacerbations. Lancet 2010;376:826-34.

20 Sbihi H, Boutin RC, Cutler C, et al. Thinking bigger: how earlylife environmental exposures shape the gut microbiome and influence the development of asthma and allergic disease. Allergy 2019;74:2103-15.

21 Leiria LOS, Martins MA, Saad MJA. Obesity and asthma: beyond $\mathrm{T}(\mathrm{H}) 2$ inflammation. Metabolism 2015;64:172-81.

22 Hedman L, Bjerg A, Sundberg S, et al. Both environmental tobacco smoke and personal smoking is related to asthma and wheeze in teenagers. Thorax 2011;66:20-5.

23 Papi A, Brightling C, Pedersen SE, et al. Asthma. Lancet 2018;391:783-800.

24 Enríquez-de-Salamanca A, Bonini S, Calonge M. Molecular and cellular biomarkers in dry eye disease and ocular allergy. Curr Opin Allergy Clin Immunol 2012;12:523-33.

25 Chen L, Pi L, Fang J, et al. High incidence of dry eye in young children with allergic conjunctivitis in Southwest China. Acta Ophthalmol 2016;94:e727-30.

26 Villani E, Rabbiolo G, Nucci P. Ocular allergy as a risk factor for dry eye in adults and children. Curr Opin Allergy Clin Immunol 2018;18:398-403.

27 Heck S, Al-Shobash S, Rapp D, et al. High probability of comorbidities in bronchial asthma in Germany. NPJ Prim Care Respir Med 2017;27:017-26.

28 Masuda S, Fujisawa T, Katsumata $\mathrm{H}$, et al. High prevalence and young onset of allergic rhinitis in children with bronchial asthma. Pediatr Allergy Immunol 2008;19:517-22.

29 Huang Y-C, Chan W-C, Wang J-D, et al. Association between dry eye disease and asthma: a nationwide population-based study. PeerJ 2018;6:e5941.

30 Chia E-M, Mitchell P, Rochtchina E, et al. Prevalence and associations of dry eye syndrome in an older population: the blue Mountains eye study. Clin Exp Ophthalmol 2003;31:229-32.

31 Moher D, Liberati A, Tetzlaff J, et al. Preferred reporting items for systematic reviews and meta-analyses: the PRISMA statement. PLoS Med 2009;6:21

32 GA Wells, B.S, O'Connell D, Peterson J, et al. The Newcastle-Ottawa Scale (NOS) for assessing the quality of nonrandomised studies in meta-analyses. Available: http://www.ohri.ca/programs/clinical_ epidemiology/oxford.asp

33 Program TA. Agency for healthcare research and quality. Available: http://www.ahrq.gov/research/findings/ta/index.html

34 Higgins JPT, Thompson SG, Deeks JJ, et al. Measuring inconsistency in meta-analyses. BMJ 2003;327:557-60.

35 Wang T-J, Wang I-J, Hu C-C, et al. Comorbidities of dry eye disease: a nationwide population-based study. Acta Ophthalmol 2012;90:663-8.

36 Vehof J, Kozareva D, Hysi PG, et al. Prevalence and risk factors of dry eye disease in a British female cohort. $\mathrm{Br} J$ Ophthalmol 2014;98:1712-7.

37 Alshamrani AA, Almousa AS, Almulhim AA, et al. Prevalence and risk factors of dry eye symptoms in a Saudi Arabian population. Middle East Afr J Ophthalmol 2017;24:67-73.

38 Dogru M, Gunay M, Celik G, et al. Evaluation of the tear film instability in children with allergic diseases. Cutan Ocul Toxicol 2016;35:49-52.

39 Bielory L. Ocular toxicity of systemic asthma and allergy treatments. Curr Allergy Asthma Rep 2006;6:299-305.

40 Paulsen AJ, Cruickshanks KJ, Fischer ME, et al. Dry eye in the beaver dam offspring study: prevalence, risk factors, and healthrelated quality of life. Am J Ophthalmol 2014;157:799-806.

41 Wong J, Lan W, Ong LM, et al. Non-hormonal systemic medications and dry eye. Ocul Surf 2011;9:212-26.

42 Ousler GW, Wilcox KA, Gupta G, et al. An evaluation of the ocular drying effects of 2 systemic antihistamines: loratadine and cetirizine hydrochloride. Ann Allergy Asthma Immunol 2004;93:460-4.

43 Galor Aet al. Dry eye in the Beaver dam offspring study: prevalence, risk factors, and health-related quality of life. Am J Ophthalmol 2011;152:377-84.

44 Paulsen AJ, Cruickshanks KJ, Fischer ME, et al. Dry eye in the Beaver dam offspring study: prevalence, risk factors, and healthrelated quality of life. Am J Ophthalmol 2014;157:799-806.

45 Galor A, Kumar N, Feuer W, et al. Environmental factors affect the risk of dry eye syndrome in a United States veteran population. Ophthalmology 2014;121:972-3.

46 Idarraga MA, Guerrero JS, Mosle SG, et al. Relationships between short-term exposure to an indoor environment and dry eye (de) symptoms. J Clin Med 2020;9:1316.

47 Lukcso D, Guidotti TL, Franklin DE, et al. Indoor environmental and air quality characteristics, building-related health symptoms, and 
worker productivity in a federal government building complex. Arch Environ Occup Health 2016;71:85-101.

48 Fanger PO. Indoor air quality in the 21st century: search for excellence. Indoor Air 2000;10:68-73.

49 Wolkoff P. Ocular discomfort by environmental and personal risk factors altering the precorneal tear film. Toxicol Lett 2010;199:203-12.

50 Mo Z, Fu Q, Lyu D, et al. Impacts of air pollution on dry eye disease among residents in Hangzhou, China: a case-crossover study. Environ Pollut 2019;246:183-9.

51 Novaes P, Saldiva PHdoN, Matsuda M, et al. The effects of chronic exposure to traffic derived air pollution on the ocular surface. Environ Res 2010;110:372-4.

52 Kim Y, Paik HJ, Kim MK, et al. Short-Term effects of ground-level ozone in patients with dry eye disease: a prospective clinical study. Cornea 2019;38:1483-8.

53 Yang Q, Li K, Li D, et al. Effects of fine particulate matter on the ocular surface: an in vitro and in vivo study. Biomed Pharmacother 2019;117:109177.

54 Tan G, Li J, Yang Q, et al. Air pollutant particulate matter 2.5 induces dry eye syndrome in mice. Sci Rep 2018;8:17828.

55 Wolkoff P. Indoor air humidity, air quality, and health - An overview. Int J Hyg Environ Health 2018;221:376-90.

56 Wolkoff P, Kjaergaard SK. The dichotomy of relative humidity on indoor air quality. Environ Int 2007;33:850-7.

57 Gibson PG, McDonald VM. Management of severe asthma: targeting the airways, comorbidities and risk factors. Intern Med $\mathrm{J}$ 2017;47:623-31.

58 Guida G, Riccio AM. Immune induction of airway remodeling. Semin Immunol 2019;46:101346.
59 Barabino S, Chen Y, Chauhan S, et al. Ocular surface immunity: homeostatic mechanisms and their disruption in dry eye disease. Prog Retin Eye Res 2012;31:271-85.

60 Wei Y, Asbell PA. The core mechanism of dry eye disease is inflammation. Eye Contact Lens 2014;40:248-56.

61 Yamaguchi T. Inflammatory response in dry eye. Invest Ophthalmol Vis Sci 2018;59:DES192-23651.

62 Reyes JL, Vannan DT, Eksteen B, et al. Innate and adaptive cell populations driving inflammation in dry eye disease. Mediators Inflamm 2018;2018:1-12.

63 Neto HJC, Rosário NA, Westphal GLC, et al. Allergic conjunctivitis in asthmatic children: as common as underreported. Ann Allergy Asthma Immunol 2010;105:399-400.

64 Onguchi T, Dogru M, Okada N, et al. The impact of the onset time of atopic keratoconjunctivitis on the tear function and ocular surface findings. Am J Ophthalmol 2006;141:569-71.

$65 \mathrm{Hu}$ Y, Matsumoto Y, Dogru M, et al. The differences of tear function and ocular surface findings in patients with atopic keratoconjunctivitis and vernal keratoconjunctivitis. Allergy 2007;62:10.1111/j.1398-9995.2007.01414.x:917-25.

66 Baudouin C. Formes frontières de l'allergie [Conditions bordering on allergy]. J Fr Ophtalmol 2007;30:306-13.

67 Hom MM, Nguyen AL, Bielory L. Allergic conjunctivitis and dry eye syndrome. Ann Allergy Asthma Immunol 2012;108:10.1016/j. anai.2012.01.006:163-6.

68 Uchino M, Nishiwaki Y, Michikawa T, et al. Prevalence and risk factors of dry eye disease in Japan: Koumi study. Ophthalmology 2011;118:2361-7.

69 Gomes JAP, Azar DT, Baudouin C, et al. TFOS DEWS II iatrogenic report. Ocul Surf 2017;15:511-38. 